\title{
Por que devemos nos preocupar com a saúde bucal de crianças hospitalizadas?
} Why should we care about hospitalized children's oral health?

No ambiente hospitalar, as crianças internadas estão sujeitas a uma série de fatores que contribuem negativamente para a sua saúde bucal. Isso se dá, em grande parte, porque a atenção da equipe médica e de enfermagem está voltada para o tratamento das doenças que levaram a criança à hospitalização. Em adição a isso, a mudança drástica nos horários das refeições e nos hábitos alimentares, a introdução de medicamentos na rotina diária, o estresse pela hospitalização, a indisposição ocasionada pela doença e a estadia em um ambiente diferente do habitual levam à subvalorização dos cuidados bucais. Se pensarmos, no entanto, que a cavidade bucal é um nicho de proliferação bacteriana, com os mais diversos substratos, e que pode desencadear não só problemas bucais, como também agravar a saúde sistêmica, essas preocupações se transportam para a esfera da saúde pública.

As condições de saúde bucal de crianças hospitalizadas são preocupantes por diversas razões. $\mathrm{O}$ primeiro motivo de inquietação é a observação da relação positiva entre o aumento da suscetibilidade aos principais problemas bucais, como cárie dental e doença periodontal, e o período de internação. Segundo Amaral ${ }^{1}$, a partir de três dias, crianças hospitalizadas apresentavam um índice de placa médio de $67,7 \%$. A partir de cinco dias, o valor chegava a $100 \%$, sendo que o ideal é que haja uma prevalência de até $10 \%^{2}$. O biofilme dental mensurado pelo índice é precursor da cárie e da doença periodontal e se forma quando as superfícies dentárias não são devidamente higienizadas. Portanto, esses pacientes apresentavam um risco maior de desenvolver tais doenças.

Outro motivo de preocupação é a constatação de que a maior parte da medicação infantil apresenta a sacarose como principal edulcorante na sua formulação ${ }^{3}$. Esse carboidrato torna o medicamen-

\begin{abstract}
Marcos José Custodio Neto da Silva', Cyrene Piazera Silva Costa ${ }^{2}$, Francileia de Almeida Oliveira de Sá ${ }^{3}$, Lucyana de Oliveira Borges ${ }^{4}$, Tetis Serejo Sauáia ${ }^{5}$
\end{abstract}

\section{Resumo}

Crianças, quando transferidas para o ambiente hospitalar, estão sujeitas a uma série de fatores desfavoráveis à saúde bucal. O objetivo deste estudo foi identificar a contribuição do cirurgião-dentista na melhoria da higiene bucal de crianças hospitalizadas. Como metodologia, foi realizada uma pesquisa bibliográfica nas bases de dados Bireme e Pubmed. Como resultados, pôde-se observar que a atenção da equipe médica está voltada para o tratamento das doenças sistêmicas que motivaram as crianças à hospitalização. As condições de higiene oral são negligenciadas, aumentando a suscetibilidade aos principais problemas orais, especialmente cárie e doença periodontal, que podem resultar em agravamento no quadro de saúde destes pacientes. Concluiu-se que é de extrema importância que medidas educativas e preventivas sejam implantadas no intuito de evitar o aparecimento de complicações orais. Essas envolvem ações esclarecedoras aos cuidadores e médicos sobre o potencial cariogênico e erosivo da medicação pediátrica, instruções à equipe de enfermagem quanto à higiene bucal e conscientização dos responsáveis a respeito da influência dos problemas orais na saúde geral, além da presença do dentista no hospital.

Palavras-chaves: Saúde bucal; Criança; Hospitalização

Área Temática: Saúde

Linha da Extensão: Pessoas com deficiência, incapacidades e necessidades especiais; Infância e adolescência; Saúde humana

Acadêmico do $6^{\circ}$ período do curso de Odontologia da Universidade Federal do Ma ranhão; Voluntário do projeto de extensão "Orientação a higiene bucal de crianças internadas no Hospital Infantil Dr. Juvêncio Mattos"; E-mail: marcos sk8er4@hotmail. inter

Acadêmica do Programa de Pós-graduação em Odontologia da Universidade Federal do Maranhão; Co-coordenadora do projeto de extensão "Orientação a higien bucal de crianças internadas no Hospital Infantil $\mathrm{Dr}$. Juvêncio Mattos".; E-mail: cyrenepiazera@hotmail.com.

Acadêmica do $6^{\circ}$ período do curso de Odontologia da Universidade Federal do Maranhão; Voluntária do projeto de extensão "Orientação a higiene bucal de crianças internadas no Hospital Infantil Dr. Juvêncio Mattos"; E-mail: leya.oliver@hotmail.com. Acadêmica do $6^{\circ}$ período do curso de Odontologia da Universidade Federal do Maranhão; Voluntária do projeto de extensão "Orientação a higiene bucal de crianças internadas no Hospital Infantil Dr. Juvêncio Mattos"; E-mail: lucyana.borges@gmail.com. Professora Doutora da disciplina de Endodontia do curso de Odontologia da Universidade Federal do Maranhāo; Coordenadora do projeto de extensăo "Orientaçao a tsquaia@uol.com.br. 
to mais aceitável porque mascara o gosto desagradável que a maioria apresenta, além de conservar a formulação, conferir viscosidade e torná-lo menos oneroso, o que influencia no valor final do produto $^{4}$. Todavia, a saúde dental pode ser prejudicada ${ }^{5}$, pois as bactérias do biofilme fermentam a sacarose e convertem-na em ácidos desmineralizantes, se constituindo em um fator participativo para o aparecimento da cárie dental ${ }^{6}$, principalmente de cárie severa na infância $(\mathrm{CSI})^{7}$. Os medicamentos pediátricos, especialmente os xaropes, também apresentam ph endógeno baixo, geralmente inferior ao ph crítico de dissolução do esmalte ${ }^{8}$, fato que favorece a aceleração de perdas minerais e confere ao medicamento tanto potencial cariogênico como erosivo, ${ }^{90}$. Em algumas medicações ainda há a diminuição do fluxo salivar como um efeito colatera ${ }^{11}$. A saliva é importante na autolimpeza bucal, no equilíbrio ecológico das bactérias, na neutralização dos ácidos gerados pelo biofilme dental e no equilíbrio do processo de desmineralização-remineralização do dente ${ }^{12}$. Assim, o fluxo salivar qualitativa e quantitativamente normal auxiliaria na reversão dos quadros iniciais de cárie. Em todos os sentidos, a medicação pediátrica, acrescida ao seu tempo de uso e higiene oral deficiente, tem potencial para aumentar a prevalência de cárie dental.

Os cuidados com a higiene bucal de crianças hospitalizadas estão na dependência dos pais e/ou responsáveis, se constituindo em outro motivo de preocupação, visto que a maioria dos responsáveis não estimula e nem é estimulada a escovar os dentes e utilizar fio dental em seus dependentes. $\mathrm{O}$ problema não se restringe à falta de higiene após a alimentação, mas também à falta de escovação depois da administração de medicamentos açucarados. Sendo o potencial cariogênico e erosivo dos medicamentos estabelecido, se nenhuma medida eficaz de higiene bucal é realizada, o risco da ocorrência das doenças orais torna-se ainda maior. $\mathrm{Ne}$ ves $^{13}$ mostrou que $70,9 \%$ dos acompanhantes das crianças associaram o uso de medicamentos pediátricos com o desenvolvimento de lesões cariosas. Porém, destes, 78,7\% não realizavam a higiene bucal na criança após o uso dos mesmos.

Segundo Marquezan ${ }^{14}, 32,5 \%$ dos pais davam medicamentos interrompendo o sono da criança. Destes, 100 \% não realizavam a escovação nas crianças após a sua administração, propiciando um contato prolongado da sacarose com os dentes, em razão da hipossalivação no período do sono, bem como a redução da atividade muscular e da deglutição ${ }^{15}$. Percebe-se que a relação causa-efeito não é claramente estabelecida pelos responsáveis dos pacientes e que estes não enxergam nos cuidados bucais uma necessidade ${ }^{16}$. Outra barreira aos cuidados dentais é o desconhecimento dos responsáveis quanto à correta forma de higienização, já que o fio dental, importante na remoção mecânica do biofilme nos espaços interproximais, raramente é mencionado como participante da higiene oral dessas crianças ${ }^{17}$.

As condições de saúde bucal de crianças internadas são também preocupantes devido à existência de relações estabelecidas na literatura, desde a antiguidade, entre as doenças bucais e o aparecimento de doenças sistêmicas. No Egito Antigo, por exemplo, o papiro Ebers já responsabilizava os dentes pela ocorrência de dores de cabeça, ombros e pés e, para restabelecer a saúde era preciso extirpar os dentes. As bactérias do biofilme dental e lesões infecciosas podem se aprofundar nos tecidos e acessar a circulação linfática e sanguínea, causando bacteriemias e, assim, alcançando outros órgãos ${ }^{18}$. A literatura odontológica relaciona as doenças bucais com o aparecimento de endocardite bacteriana $^{19}$, aterosclerose ${ }^{20,21}$, enfarte do miocárdio e eventos cérebro-vasculares ${ }^{22}$, trombos e isquemia coronária ${ }^{23}$, abscesso cerebral ${ }^{24}$, pneumonia bacteriana, doença pulmonar obstrutiva crônica e artrite reumatóide ${ }^{25}$, desnutrição $0^{26}$, infecções em artefatos ortopédicos ${ }^{27}$ e interferências no controle do diabetes mellitus ${ }^{28}$. Desse modo, uma criança internada, cujo organismo já se encontra debilitado, poderá ainda ter seu quadro de saúde exacerbado pelo surgimento de outras doenças, incluindo as bucais, além daquelas responsáveis pela hospitalização. As consequências diretas são períodos mais longos de tratamento e retardo da recuperação, além da possibilidade de óbito.

Todas as apreensões listadas corroboram o fato de que no ambiente hospitalar existe um maior risco de desenvolvimento das doenças orais, especialmente cárie e doença periodontal, focos de disseminação de microorganismos patogênicos capazes de desequilibrar a homeostasia do organismo e comprometer a saúde geral da criança. Sendo assim, é de extrema importância que a higiene bucal desses pacientes, mesmo que em um ambiente hostil para sua reprodução, como o hospitalar, não seja descuidada. A implantação de 
algumas medidas simples poderia ajudar a mitigar o aparecimento dessas complicações. De início, os médicos deveriam ser informados do potencial cariogênico da medicação infantil e aconselhados a prescrever aqueles fármacos livres de açúcar. Como de fato poucos desses medicamentos são sugar-free, incluindo os genéricos, os pediatras deveriam pelo menos orientar os pais sobre os efeitos adversos da medicação adocicada e de baixo ph somada à falta de escovação. As próprias equipes de enfermagem da ala pediátrica deveriam ser instruídas sobre esses problemas, pois estas poderiam auxiliar na conscientização dos pais e também estimular a reprodução dos hábitos bucais saudáveis nas crianças. Por fim, deveria existir um profissional da odontologia especializado dentro do hospital, que atuasse juntamente ao médico e enfermeiros em uma equipe multidisciplinar de tratamento aos pacientes infantis. Este, além de supervisionar as ações de médicos e enfermeiros quanto aos cuidados bucais, estaria disponível para tratar quando necessário e realizar medidas profiláticas, visando suprimir focos locais de doenças, antes que estes desencadeiem maiores problemas de ordem sistêmica. A participação do dentista também se estenderia na orientação aos acompanhantes dos pacientes infantis, pois estes devem estar conscientes de suas necessidades e responsabilidades na manutenção da saúde tanto bucal como geral, seja no hospital ou além do ambiente clínico. Essas medidas são simples, mas essenciais se o objetivo é prevenir complicações de ordem local e geral em pacientes que apresentam debilidade no organismo, motivo pelo qual se encontram no hospital. Tais ações de orientação, prevenção e tratamento incluiriam o dentista em um meio onde a Odontologia foi esquecida ou negligenciada e, dessa forma, agiriam como atenuante dos problemas bucais no contexto hospitalar.

\section{Referências}

1. AMARAL, K.C.; TENORIO, M.D.A.; DANTAS, A.B. Condição de saúde bucal de crianças internas em hospitais da cidade de Maceió-AL. Odontol. clín.cient., Recife, v.5, n.4, p.267-273, out./dez. 2006.

2. O'LEARY, T.J.; DRAKE, R.B.; NAYLOR, J.E. The plaque control record. J. periodontol., Indianápolis, v.43, n.1, p.38, jan. 1972.

3. NEIVA, A. et al. Análise in vitro da concentração de sacarose e $\mathrm{pH}$ de antibacterianos de uso pediátrico. Pesqui. bras. odontopediatria clín. integr., João Pessoa, v.1, n.1, p.9-16, 2001.
4. BALBANI, A.P.S.; STELZER, L.B.; MONTOVANI, J.C. Excipientes de medicamentos e as informações da bula. Rev. bras. otorrinolaringol., São Paulo, v.72, n.3, p.400-6, 2006.

5. COSTA, C.C. et al. Análise do pH endógeno, da acidez e da concentração de sacarose de medicamentos pediátricos. Rev. odonto ciênc., Porto Alegre, v.19, n.44, p.164-9, 2004.

6. LIMA, José Eduardo de Oliveira.Cárie dentária:um novo conceito. Rev. dent. press ortodon. ortopedi. facial, Maringá, v.12, n.6, p.119-130, 2007.

7. LOSSO, E.M. et al.Cárie precoce e severa na infância: uma abordagem integral. J. pediatr., Rio de Janeiro, v.85, n.4, p.295-300, 2009.

8. PASSOS, I.A.; FREITAS, C.H.S.M.; SAMPAIO, F.C. Potencial cariogênico de medicamentos pediátricos - papel na etiologia da cárie dentária. J. Health Sci. Inst., São Paulo, v.26, n.1, p. 125-9, 2008.

9. SANTINHO, A.J.P.; WALDOW, C.; DOS SANTOS, S.B. Estudo sobre a correlação do potencial cariogênico e do $\mathrm{pH}$ de xaropes pediátricos.Rev. bras. farm., Rio de Janeiro, v.89, n.2, p.88-90, 2008.

10. FEIGA, R.J.; JENSEN, M.E.; MENSING, C.A. Dental caries potential of liquid medications. J. pediatr., Saint Louis, v.68, n.3, p.416-9, 1981.

11. FELDENS, C.A. Cárie oclusal: diagnóstico, prevenção e tratamento. JBP, $\mathbf{j}$. bras. odontopediatr. odontol. bebê, Curitiba, v.1, n.4, p.56-61, out./dez. 1998.

12. TABAK, L.A.; BOWEN, W.H. Molecular biological approaches to caries: role of saliva. In: Bowen, W.H. Cariology for the nineties. 1. ed. New York: University of Rochester Press, 1993. p. 63-70. Disponível em: < http://books.google.com.br/books?id=G e2osTX6hkUC\&pg=PA63\&lpg=PA63\&dq=tabak $+\mathrm{m}$ olecular+biological +approaches+to+caries+role + of + saliva\&source $=$ bl\&ots $=\mathrm{jxB} 68 \mathrm{~J} 8 \mathrm{O}$ sR \& sig $=0 \mathrm{f} 7 \mathrm{WOlhcy}$ 7ha0xaMqWn2aEDKxUg\&hl=pt-BR\&ei=lq7UTOSF G4OKlwea64iDCQ\&sa $=X \&$ oi $=$ book_result $\& c t=$ resu $1 \mathrm{t} \&$ resnum $=1 \&$ ved $=0$ CBsQ6AEwAA\# > . Acesso em 20 jul. 2010.

13. NEVES,B.G. et al. Percepções e atitudes de responsáveis por crianças frente ao uso de medicamentos infantis e sua relação com cárie e erosão dentária. Ciênc. saúde coletiva, Rio de janeiro, v.12, n.5, p.1295-1300, 2007.

14. ARQUEZAN, M. et al. Medicamentos utilizados por pacientes odontopediátricos e seu potencial cariogênico. RPG rev. pos-grad., São Paulo, v.13, n.4, p.334-9, 2007.

15. DE MENEZES, V.A. et al. Pediatric medicines and their relationship to dental caries. Braz. j. pharm. sci., São Paulo, v. 46, n. 1, p.157-164, jan. /mar. 2010.

16. NICOPOULOS, M. et al. Oral health needs and barriers to dental care in hospitalized children. Spec. care dentist., Chicago, v.27, n.5, p. 206-11, 2007.

17. XIMENES, R.C.C.; ARAGAO, D.S.F.; COLA- 
RES, V. Avaliação dos cuidados com a saúde oral de crianças hospitalizadas. Rev. Fac. Odontol., Porto Alegre, v. 49, n. 1, p. 21-25, jan./abr. 2008.

18. DE LORENZO, J.L.. Recuperação Sistêmica das Doenças Infecciosas da Boca. In:__. Microbiologia para o estudante de odontologia. 1. ed. São Paulo: Athena, 2004.

19. BACK, E.; SVAMBOM, M. Bacterial endocarditis of oral origin. Swed. Dent. J., Jonkoping, v.4, n.1-2, p.69-77, 1980.

\section{AMERICAN ACADEMY OF PERIODONTOL-} OGY. Periodontal disease as a potential risk for systemic diseases. J. periodontol., Indianápolis, v.69, n.7, p. 841-850, 1998.

21. AMERICAN DENTAL ASSOCIATION. Oral bacteria found in arterial plaque. J. am. dent. assoc., Chicago, v.136, n.6, p. 724-725, jun.2005.

22. SOORY, M. Periodontal Disease Severity and Systemic Diseases Prevalent in a Caribbean Catchment Area of Patients. West Indian med. j., Kingston, v.56, n.2, p. 190-3, 2007.

23. BARILLI, A.L.A. et al. Periodontal Disease in Patients with Ischemic Coronary Atherosclerosis at a University Hospital. Arq. bras. cardiol., São Paulo, v.87, n.6, p. 635-640, 2006.

24. DE MORAIS, T.M.N. et al. Importância da Atuação Odontológica em Pacientes Internados em Unidade de Terapia Intensiva. Rev. bras. ter. intensiva., Rio de Janeiro, v.18, n.4, p.412-417, out./dez. 2006.

25. ALMEIDA, R.F. et al. Associação entre doença periodontal e patologias sistêmicas. Rev. Port. clin. geral, Lisboa, v.22, n.3, p.379-90, 2006.

26. MANGAN, D.F. Nutrition and oral infectious diseases: connections and future research. Compend. contin. educ. dent., Jamesburg, v.23, n.5, p.416-438, maio 2002

27. AMERICAN DENTAL ASSOCIATION; AMERICAN ACADEMY OF ORTHOPAEDIC SURGEONS. Antibiotic prophylaxis for dental patients with joints replacements. J. am. dent. assoc., Chicago, v.134, n.7, p.895-9, jul. 2003.

28. WEIDLICH, P. et al. Association between periodontal diseases and systemic diseases. Braz. oral res., São Paulo, v.22, n.1, p. 32-43, 2008.

\begin{abstract}
Children transferred to the hospital environment are vulnerable to a series of unfavorable factors to their oral health. This study aims to identify the dentist's contribution to the improvement of hospitalized children's oral health. Bibliographic research was performed to the Bireme and Pubmed data base. We found that medical team's attention is focused on the treatment of those diseases that led children to the hospital. Oral health conditions are neglected, increasing susceptibility to the main oral problems, specially dental caries and periodontal disease, which can aggravate infantile patients health status. In conclusion, it is extremely important to introduce educational and preventive measures in order to avoid the appearance of oral problems. These measures involve elucidative actions to caregivers and doctors about cariogenic and erosive potential of pediatric medication, instructions to nurses concerning oral health cares and making the adult responsible aware of the influence of oral health in systemic health, besides the presence of a dentistry professional in the hospital. Keywords: Oral health; Child; Hospitalization
\end{abstract}

